\title{
Surgical Management of Non-small Cell Lung Cancer with Solitary Hematogenous Metastases
}

\author{
GRIGORIOS KARAGKIOUZIS ${ }^{1}$, ELEFTHERIOS SPARTALIS ${ }^{2}$, DEMETRIOS MORIS ${ }^{3}$, \\ DEMETRIOS PATSOURAS ${ }^{2}$, ATHANASIOS ATHANASIOU ${ }^{1}$, IOANNIS KARATHANASIS ${ }^{1}$, \\ ALEXIOS VERVENIOTIS ${ }^{1}$, FROSO KONSTANTINOU ${ }^{4}$, ILIAS A. KOUERINIS ${ }^{5}$, \\ KONSTANTINOS POTARIS $^{1}$, DIMITRIOS DIMITROULIS ${ }^{2}$ and PERIKLIS TOMOS ${ }^{2}$ \\ ${ }^{1}$ Department of Thoracic Surgery, Sotiria Hospital for Chest Diseases, Athens, Greece; \\ ${ }^{2}$ Second Department of Propedeutic Surgery, Laikon Hospital, Athens School of Medicine, Athens, Greece; \\ ${ }^{3}$ Department of Surgery, The Ohio State University Comprehensive Cancer Center, \\ The Ohio State University, Columbus, OH, U.S.A.; \\ ${ }^{4}$ Department of Internal Medicine, Sotiria Hospital for Chest Diseases, Athens, Greece; \\ ${ }^{5}$ First Department of Cardiothoracic Surgery, Hippokration Hospital, Athens, Greece
}

\begin{abstract}
Background/Aim: The treatment of patients with solitary hematogenous metastases from non-small cell lung cancer (NSCLC) remains controversial, although numerous retrospective studies have reported favorable results for patients offered combined surgical therapy. Our aim was to determine the role of surgical resection in the management of NSCLC with solitary extrapulmonary metastases and to investigate for possible prognostic factors. Patients and Methods: Between January 2004 and December 2012, 12 patients with NSCLC, from two Institutions, underwent metastasectomy for their solitary metastatic lesion. Sites of metastases included brain ( $n=3)$, adrenal gland $(n=6)$, thoracic wall $(n=2)$ and diaphragm $(n=1)$. All patients had undergone pulmonary resections for their primary NSCLC. Results: Median survival for the entire cohort was 24.1 months, whereas 1- and 5-year survival rates were $73 \%$ and $39 \%$, respectively. Patients with stage III intrathoracic disease had significantly worse survival than those with lower tumor stage. A tendency for adenocarcinomatous histology to positively affect survival was recognized, although it was proven not to be statistically significant. Conclusion: Despite the retrospective nature of our study
\end{abstract}

This article is freely accessible online.

Correspondence to: Demetrios Moris, MD, M.Sc., Ph.D., MACS, Lerner Research Institute, Cleveland Clinic, 9500 Euclid Ave., NE60, Cleveland, Ohio 44195, U.S.A. Tel: +1 2164442574, Fax: +1 2164454658, e-mail: dimmoris@yahoo.com

Key Words: Adrenal metastasis, brain metastasis, non-small cell lung cancer, surgery. and the small cohort size, it is emerging that combined surgical resection might offer patients with NSCLC with solitary hematogenous metastases a survival benefit. Limited intrathoracic disease and adenocarcinomatous histology might be associated with better outcomes.

Stage IV disease at initial presentation accounts for approximately $41 \%$ of newly-diagnosed cases with non-small cell lung cancer (NSCLC) (1). Prognosis for metastatic lung cancer remains dismal, despite continuously emerging treatment options. Although the majority of patients have disseminated metastatic disease at diagnosis, a small percentage are found to have a solitary metastasis. In addition any patients with NSCLC who previously received definitive treatment may experience metachronous solitary distant recurrence during the course of their disease. This poorly understood state of limited metastatic load has been described as oligometastatic disease and it seems to run a more indolent course $(2,3)$. Retrospective clinical studies focused on the surgical management of solitary extrapulmonary metastases, have reported favorable results (4).

The aim of this retrospective study was to review our experience with patients who underwent resection of primary NSCLC and solitary extrapulmonary metastasis, and to analyze prognostic factors affecting survival.

\section{Patients and Methods}

We reviewed the medical records of thoracic surgical Departments at Laikon General Hospital of Athens and Sotiria Hospital for Chest Diseases (former Second Department of Thoracic Surgery) from January 2004 to December 2012 for patients with NSCLC having undergone combined resections (including stereotactic radiosurgery) of primary lung tumor and solitary hematogenous metastasis. 
Table I. Categorical variables that were studied in univariate analysis and corresponding p-values.

\begin{tabular}{lc}
\hline Categorical variable & $p$-Value \\
\hline Timing of metastatic presentation: Synchronous versus metachronous & 0.52 \\
Type of resection: Pneumonectomy versus less than pneumonectomy & 0.172 \\
Tumor histology: Adenocarcinoma versus non adenocarcinomatous NSCLC & 0.097 \\
Lymph nodal status: Absence of lymph node disease (N0) versus lymph node disease (N1 or N2) & 0.455 \\
Locoregional stage: Stage III versus stage less than III (I $\eta$ II) & 0.05 \\
Site of metastatic disease: Brain versus adrenal versus chest wall-diaphragm & 0.526 \\
\hline
\end{tabular}

Patients with histologically-proven extrapulmonary metastasis and absence of other metastatic foci (confirmed by brain, thoracic and abdominal computed tomographic imaging and bone scanning) were included in our study. Data were collected from patient medical charts, operative notes and pathologic examination records. Followup data were gathered from outpatient clinic records and with direct telephone contact with the patients or their families.

Metastases that were present at initial diagnosis or were diagnosed during the first 6 months following primary tumor resection were considered synchronous. Metastases diagnosed after that 6-month time interval were classified as metachronous. In order to address the influence of the extent of locoregional disease on survival, we assessed the locoregional disease stage (neglecting $\mathbf{M}$ status). This corresponded to the initial stage for patients with metachronous metastasis or the locoregional stage for those with synchronous metastatic disease.

Overall survival was defined as the time interval from the date of the last surgical intervention to the date of death or last followup. Three patients were lost during follow-up. For those patients, the time of the last outpatient visit was used as the endpoint.

Data were analyzed using the statistical package PASW 18 (IBM Corp., Armonk, NY, USA). Survival was estimated by the KaplanMeier method and the statistical significance of differences between subgroups was calculated using the log-rank test. $p$-Values of less than 0.05 were considered statistically significant.

\section{Results}

Between January 2004 and December 2012, 12 patients with NSCLC underwent solitary metastasectomy. All patients were males, with a median age of 61 years (range=49-67 years). Six patients had lung adenocarcinoma, two had squamous cell carcinoma and four had large cell carcinoma. Regarding the site of metastatic presentation, metastases were adrenal in six cases, brain in three, chest wall in two and diaphragmatic in one. Presentation was synchronous in seven patients and metachronous in five. Regarding mediastinal lymph node involvement, six patients had N0, three had N1 and three had N2 disease. The disease stage without taking into account the $M$ status was IA in four patients, IB in one, IIA in two and IIIA in six.

For the treatment of solitary metastasis, six patients underwent unilateral adrenalectomy (performed by flank approach), one patient underwent craniotomy, two were treated with stereotactic radiosurgery, two underwent chest wall resection and one underwent limited diaphragmatic resection. Pulmonary resection included lobectomy in seven patients, pneumonectomy in three, lobectomy combined with wedge resection of adjacent lung parenchyma in one, and wedge resection in one. The 30-day mortality was $0 \%$. All patients received adjuvant chemotherapy. Patients with brain metastasis received postoperative whole-brain radiation therapy.

The median follow-up period for the entire cohort was 13.55 months (confidence interval=4.04-23.02 months). At the time of analysis, six patients were alive and disease-free, one patient was alive with liver metastases, two had died and three were lost during follow-up. The median survival was 24.1 months. Survival rates at 1 and 5 years were $73 \%$ and $39 \%$, respectively.

Univariate analysis of different categorical variables (Table I) revealed that patients with locoregional tumor stage lower than III (I or II) tended to demonstrate better survival than patients with locoregional stage III $(p=0.05)$ (Figure 1). There was also a trend for patients with adenocarcinomatous tumor histology to display better survival compared with those of patients with non-adenocarcinoma, although this finding did not reach statistical significance $(p=0.097)$ (Figure 2).

The effect of time of metastatic presentation (synchronous vs. metachronous), type of pulmonary resection (pneumonectomy $v s$. lesser than pneumonectomy), mediastinal nodal status (N0 vs. N1 or N2) and site of metastatic disease on survival was found not to be statistically significant on univariate analysis.

\section{Discussion}

In accordance with previously published studies, our analysis demonstrates that combined surgical resection of primary lung tumor and solitary hematogenous metastasis is associated with improved survival. In our series, median survival was 24.1 months, whereas 1- and 5-year survival rates were $73 \%$ and $39 \%$, respectively. Many previous retrospective studies addressing the role of surgical excision for solitary brain metastases in patients with NSCLC have 


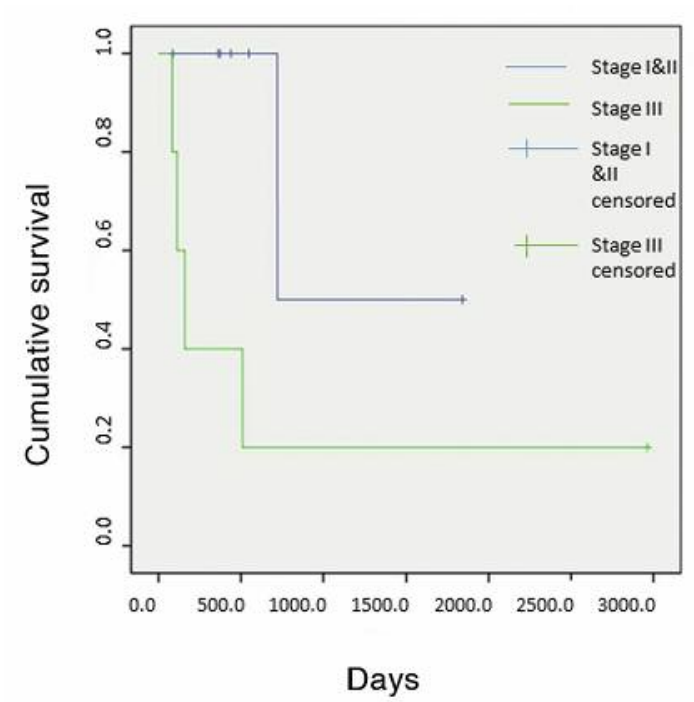

Figure 1. Kaplan-Meier survival curves comparing overall survival among patients with locoregional stage III and patients with locoregional stage lower than III (I or II). *Significantly different at $p=0.05$.

reported favorable results, with median survival of between 6.8 to 27 months and 5-year survival rates ranged from $8.3 \%$ to $45 \%$ (5-15). Similar survival benefit with a 5-year survival rate of approximately $25 \%$ was demonstrated by Tanvetyanon et al. in a systematic review studying the outcomes of adrenalectomy in patients with NSCLC with solitary adrenal metastasis (16).

In our analysis, locoregional disease stage was the only variable proven to have a statistically significant effect on survival. Patients with locoregional stage I and II had better survival than patients with stage III disease. This negative effect of advanced locoregional stage on survival has been demonstrated in previous studies. Hankins et al. reported that stage I or II (defined by $\mathrm{T}$ and $\mathrm{N}$ descriptors) was associated with better survival (10). Billing et al. reported similar results regarding the positive effect of a limited "postoperative thoracic stage" on the survival of surgically treated patients with synchronous brain metastases (14). However, this finding appears inconsistent in relevant published literature $(12,17)$, whereas many researchers did not include that variable in their analyses $(8-11,13,16,18,19)$.

Our analysis demonstrated a trend for different tumor histological types to confer different survival. Specifically, despite there being no statistical significance, there was a serious propensity $(p<0.1)$ for patients with adenocarcinoma to have improved survival compared to patients with other histological types. Bonnette and Granone reported similarly favorable results in terms of survival for adenocarcinomatous tumor pathology $(12,13)$. In other retrospective studies, however, the prognostic value of

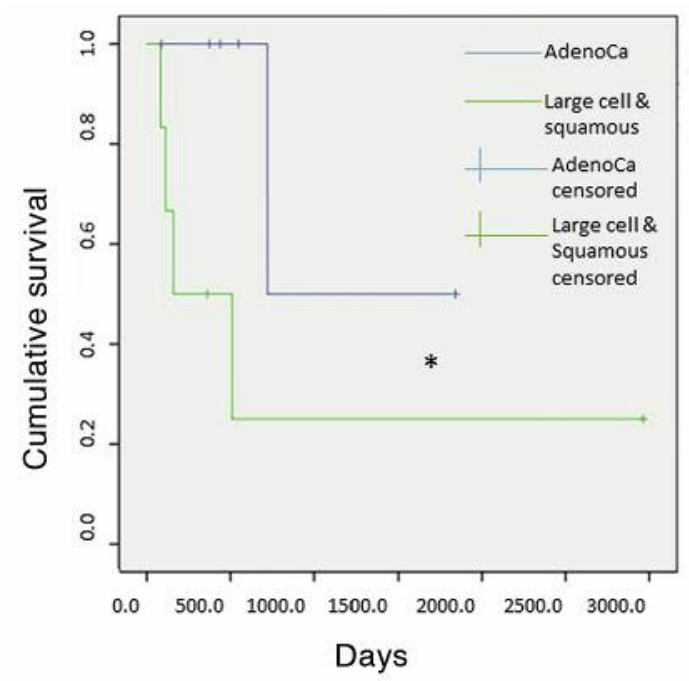

Figure 2. Kaplan-Meier survival curves comparing overall survival among patients with lung adenocarcinoma (AdenoCa) and patients with non adenocarcinomatous tumor histology. ${ }^{*}$ Significantly different at $p=0.097$.

primary tumor histology was shown not to be statistically significant $(5,8,10,11,14,15,19-21)$.

Some authors suggest that the type of pulmonary resection influences outcomes, reporting a negative impact of pneumonectomy (versus lobectomy) on survival $(8,11)$. Similar results in favor of even lesser resections (wedge) were also reported by Magilligan et al. (5). In our study, the type of lung resection was not a statistically significant predictor of survival.

Regarding the timing of metastatic presentation, Tanvetyanon et al. in their aforementioned study demonstrated that median survival was longer in patients with metachronous metastases than in those with synchronous disease (31 months vs. 12 months, respectively). Interestingly, 5-year survival rates were almost equal for both groups (approximately 25\%) (16). In the same vein, Saitoh et al. reported that an interval between pulmonary operation and brain metastasectomy of longer than 360 days was associated with improved 1-, 2-, and 3 -year survival (11). In our series, timing of metastatic relapse was not a significant determinant of survival.

There are obvious limitations to our study. The small number of patients and its retrospective nature, with the inherent distortion of the analysis from selection bias, renders generalization of our results uncertain.

Our study supports the possibility of better survival for patients with NSCLC with solitary metastasis after combined surgical resection. Results for the effect of several factors on survival remain inconclusive in existing literature. However, the majority of studies support the presumption that limited locoregional disease is associated with better prognosis. 


\section{Conclusion}

In conclusion, we recommend that patients with NSCLC with solitary hematogenous metastasis should be evaluated as possible candidates for combined surgical resection. Selection criteria should include a good performance status, a controlled or controllable primary tumor, a resectable metastatic lesion and negative further metastatic workup. Survival benefit tends to be more prevalent in patients with a limited extent of intrathoracic disease. Timing of metastatic presentation (synchronous or metachronous) and primary tumor histology should not be included in selection criteria until their effect on survival is documented.

\section{Conflicts of Interest}

The Authors declare no conflicts of interest.

\section{References}

1 Socinski MA, Crowell R, Hensing TE, Langer CJ, Lilenbaum R, Sandler AB, Morris D; American College of Chest Physicians: Treatment of non-small cell lung cancer, stage IV: ACCP Evidence-based Clinical Practice Guidelines (Second Edition). Chest 132(3 Suppl): 277S-289S, 2007.

2 Hellman S and Weichselbaum RR: Oligometastases. J Clin Oncol 13(1): 8-10, 1995.

3 Pfannschmidt $\mathrm{J}$ and Dienemann $\mathrm{H}$ : Surgical treatment of oligometastatic non-small cell lung cancer. Lung Cancer 69(3): 251-258, 2010.

4 Karagkiouzis G, Koulaxouzidis G, Tomos P, Spartalis ED, Konstantinou F, Charpidou A and Syrigos KN: Solitary metastasectomy in non-small cell lung cancer. J BUON 17(4): 712-718, 2012.

5 Magilligan DJ, Jr., Duvernoy C, Malik G, Lewis JW Jr., Knighton R and Ausman JI: Surgical approach to lung cancer with solitary cerebral metastasis: Twenty-five years' experience. Ann Thorac Surg 42(4): 360-364, 1986.

6 Read RC, Boop WC, Yoder G and Schaefer R: Management of nonsmall cell lung carcinoma with solitary brain metastasis. J Thorac Cardiovasc Surg 98(5 Pt 2): 884-890; discussion 890881, 1989.

7 Macchiarini P, Buonaguidi R, Hardin M, Mussi A and Angeletti CA: Results and prognostic factors of surgery in the management of non-small cell lung cancer with solitary brain metastasis. Cancer 68(2): 300-304, 1991.

8 Mussi A, Pistolesi M, Lucchi M, Janni A, Chella A, Parenti G, Rossi $\mathrm{G}$ and Angeletti CA: Resection of single brain metastasis in non-small-cell lung cancer: Prognostic factors. J Thorac Cardiovasc Surg 112(1): 146-153, 1996.

9 Torre M, Barbieri B, Bera E, Locicero S, Pieri Nerli F and Belloni PA: Surgical therapy in lung cancer with single brain metastasis. Eur J Cardiothorac Surg 2(5): 336-339, 1988.
10 Hankins JR, Miller JE, Salcman M, Ferraro F, Green DC, Attar $S$ and McLaughlin JS: Surgical management of lung cancer with solitary cerebral metastasis. Ann Thorac Surg 46(1): 24-28, 1988.

11 Saitoh Y, Fujisawa T, Shiba M, Yoshida S, Sekine Y, Baba M, Iizasa $\mathrm{T}$ and Kubota M: Prognostic factors in surgical treatment of solitary brain metastasis after resection of non-small-cell lung cancer. Lung Cancer 24(2): 99-106, 1999.

12 Bonnette P, Puyo P, Gabriel C, Giudicelli R, Regnard JF, Riquet M, Brichon PY and Groupe T: Surgical management of nonsmall cell lung cancer with synchronous brain metastases. Chest 119(5): 1469-1475, 2001.

13 Granone P, Margaritora S, D'Andrilli A, Cesario A, Kawamukai $\mathrm{K}$ and Meacci E: Non-small cell lung cancer with single brain metastasis: The role of surgical treatment. Eur J Cardiothorac Surg 20(2): 361-366, 2001.

14 Billing PS, Miller DL, Allen MS, Deschamps C, Trastek VF and Pairolero PC: Surgical treatment of primary lung cancer with synchronous brain metastases. J Thorac Cardiovasc Surg 122(3): 548-553, 2001.

15 Furak J, Trojan I, Szoke T, Agocs L, Csekeo A, Kas J, Svastics E, Eller $\mathrm{J}$ and Tiszlavicz L: Lung cancer and its operable brain metastasis: Survival rate and staging problems. Ann Thorac Surg 79(1): 241-247; discussion 241-247, 2005.

16 Tanvetyanon T, Robinson LA, Schell MJ, Strong VE, Kapoor R, Coit DG and Bepler G: Outcomes of adrenalectomy for isolated synchronous versus metachronous adrenal metastases in nonsmall-cell lung cancer: A systematic review and pooled analysis. J Clin Oncol 26(7): 1142-1147, 2008.

17 Beitler AL, Urschel JD, Velagapudi SR and Takita H: Surgical management of adrenal metastases from lung cancer. J Surg Oncol 69(1): 54-57, 1998.

18 Wronski M, Arbit E, Burt M and Galicich JH: Survival after surgical treatment of brain metastases from lung cancer: A follow-up study of 231 patients treated between 1976 and 1991. J Neurosurg 83(4): 605-616, 1995.

19 Porte H, Siat J, Guibert B, Lepimpec-Barthes F, Jancovici R, Bernard A, Foucart A and Wurtz A: Resection of adrenal metastases from non-small cell lung cancer: A multicenter study. Ann Thorac Surg 71(3): 981-985, 2001.

20 Getman V, Devyatko E, Dunkler D, Eckersberger F, End A, Klepetko W, Marta G and Mueller MR: Prognosis of patients with non-small cell lung cancer with isolated brain metastases undergoing combined surgical treatment. Eur J Cardiothorac Surg 25(6): 1107-1113, 2004.

21 Hunt I, Rankin SC and Lang-Lazdunski L: Combined lung resection and transdiaphragmatic adrenalectomy in patients with non-small cell lung cancer and homolateral solitary adrenal metastasis. Eur J Cardiothorac Surg 30(1): 194-195, 2006.

Received January 11, 2017

Revised February 24, 2017

Accepted March 1, 2017 